\title{
Expected Future Market Volume of HTS Equipment in South Korea
}

\author{
Jae-young Yoon ${ }^{1 *}$, Seung-ryul Lee ${ }^{1}$ B. Yang ${ }^{2}$, SeungYeup Lee ${ }^{3}$, and Youngjin Won ${ }^{3}$ \\ ${ }^{1}$ KERI, 665-4 Naeson-Dong, Uwiwang-City, Gyunggi-Do 437-808, Korea \\ ${ }^{2}$ KEPRI, 103-16 Munji-Dong, Yusung-Gu, Daejeon 305-380, Korea \\ ${ }^{3}$ KEPCO, 411 Yeongdongdaero, Gangnam-Gu, Seoul 135-791, Korea
}

(Received 15 March 2011, Received in final form 29 March 2011, Accepted 14 April 2011)

\begin{abstract}
This paper shows the entire future market volume of the HTS power industry, one of main smart grid equipment, in the case of the final market penetration ratio reaching $100 \%$ in the domestic market (South Korea). In this paper, the market penetration ratio is determined using the judgment method, with the market penetration S-curve induced using the Delphi method and the Product Life Cycle from 2011 (supposed launching year, not realistic physical year), to 2050 (expected final target year). This paper analyzes the HTS market penetration ratio of each stage, apparent innovation, early adapters, and the early/late majority and laggard stage, using the S-curve, thus calculating the total future market volume of HTS equipment in the positive sense. Finally, this paper estimates the quantitative analysis results for the HTS4-items (cable, FCL, transformer, rotation machine) of each year within the domestic market.
\end{abstract}

Keywords : HTS power equipment, HTS power market volume, HTS cable, HTS FCL, HTS transformer, HTS motor

\section{Introduction}

There are so many characteristics that define the smart grid, among them, superconductivity technology possessing the inherent nature to "optimize assets and operate efficiently", anticipate and respond to system disturbances in a self-healing manner, and provide the power quality for a range of needs in a digital economy [1,2]. These new characteristics are expected to primarily impact the Smart Grid Characteristics of "Secure Super Grids ${ }^{\mathrm{TM}}$ ". This makes superconductivity technology one of the main facilities in future smart super-grid development.

Within this framework, South Korea has developed HTS (high-temperature superconducting) power equipment, integral to overall smart-grid equipment, which includes cable, FCL (fault current limiter), transformer, and rotation machines (generator/motor). The market penetration strategy, considering modern marketing theory, is divided into two parts, an R\&D strategy as a technology development methodology and market development methodology for market penetration, as HTS equipment are new hightechnology products never applied, until now. This paper analyzes the entire future market volume of the HTS

*Corresponding author: Tel: +82-31-420-6180

Fax: +82-31-420-6189, e-mail: jyyoon@keri.re.kr power industry, based on the domestic electricity analysis reports and market analysis methodology, using the Delphi method and product life cycle. This paper shows the quantitative analysis results for the HTS4-items (cable, FCL, transformer, rotation machine) in the domestic market. All of the market volume in this paper indicates the NPV (Net Present Value) value transformed by 2011, the launching year of the HTS equipment.

\section{Methodology for Marketability Analysis}

Generally speaking, marketable studies are performed to determine the likely success of selling a particular product or service. A marketability study is likely to include potential demand, existing competitive products or services, and a recommendation of strategy.

This paper contains the following information:

- Domestic power industry review and future trends

- Total expected market volume for conventional power equipment in the domestic market

- Sales, competitors, and market shares in key market segments

The applied methodology for estimating the domestic 
market volume of HTS power equipment is indicated below, on a step-by-step basis.

\subsection{Market volume estimation of each item until 2020}

This report adopts "the prospect of power industry 2010" published by KOEMA (KOrea Electrical Manufacturers Association), which shows the total domestic market volume of conventional power equipment until 2020. This paper uses this report's results as the total market volume of each item, such as conventional power cables, transformers, and switchgears, all in US dollars.

\subsection{Market volume estimation of each item after 2020}

The estimated increase rate of the market volume is predicted to be $4.65 \%$, this is the average increase rate of power equipment from 2010 to 2020; this paper uses this increase rate of the market volume after 2020.

\subsection{Domestic market volume, South Korea}

A power industry analysis report is published by KOEMA as a domestic market volume of each item. In this case, during estimation of the market volume, the following points should be noticed on the basis of previous experience and expert opinion:

- Power cable market is estimated to be $40 \%$ of the total cable manufacturing data, based on previous experience

- Only use of the manufacturing results above a $1 \mathrm{kV}$ switchgear rating of was employed for estimating the HTS-FCL market volume

- For rotation machines (generator and motor), a rating above $750 \mathrm{~kW}$ is adopted

\subsection{Maximum penetration ratio}

The maximum penetration ratio of the HTS power equipment for each item is defined as the maximum possible ratio that can be substituted into the present power industry market, conventional power equipment to HTS items. This ratio is somewhat different from each power equipment item as: cable is $80 \%$; transformer is $30 \%$; switchgear is $5 \%$; rotation machine (generator/motor) is $20 \%$. For instance, the maximum penetration ratio of $20 \%$ for the rotation machine means there is a maximum $20 \%$ share of HTS rotation machinery in the conventional rotation machine market, where ratings above $750 \mathrm{~kW}$ are possible. These values are the key parameters for calculating the total market volume. Thus, these values should be determined very carefully. In this paper, the authors choose these values considering not only the inherent characteristics of the HTS equipment and various conv- entional power equipment statistical data, but also detailed discussions between associated HTS and power system experts in terms of applications of HTS equipment and the future power industry.

\subsection{Determination of the market penetration ratio in} a specific year

In terms of modern marketing theory, market penetration of HTS power equipment enables launching a new product with high efficiency, reliability, and eco-environmental technology into an old market that bears the dissatisfaction of customers. Even though the HTS power equipment cannot produce a new market or demand volume, they are the main facilities of the Smart Grid because HTS technology can be a solution for the serious problems of conventional power systems, such as fault current excess, transmission capacity limit, and downtown environment. This indicates that HTS power equipment can be a good alternative, which is pertinent to a new technology and the old market of the ANSOFF matrix in modern marketing theory.

When developing a new product or new technology, future market potential should be analyzed, and in this case, the market penetration ratio is the key factor that determines the possibility of future commercialization. Related to the market penetration ratio, the associated study to determine this factor has been conducted since 1960. Among these various methodologies to calculate the market penetration ratio, the judgment-method is the most popular and general tool because this is a reasonable certified methodology, considering the characteristics of new technology. The judgment method uses a simple equation based on expert experience or judgment. In general, the S-curve is applied to calculate the market penetration ratio; select parameters should be determined. With this background, this paper determines the market penetration ratio using the judgment method with an Scurve, instead of a complex model based method. The Fisher-Pry model, having simple exponential functions, was used as an S-curve in this paper.

The market penetration rate of the HTS power equipment was calculated by the Judgment method, with an Scurve in each year, as shown in Eq. (1):

$$
M(t)=\frac{k}{1+e^{-c(t-t h) / t s}}
$$

where $M(t)$ : market penetration ratio of a specific year

$$
\begin{aligned}
& k: \text { final market penetration rate (\%) } \\
& t: \text { time (target year, 2050) } \\
& t h: \text { time(year) reached at } M(t)=50 \% \text {, half the final }
\end{aligned}
$$




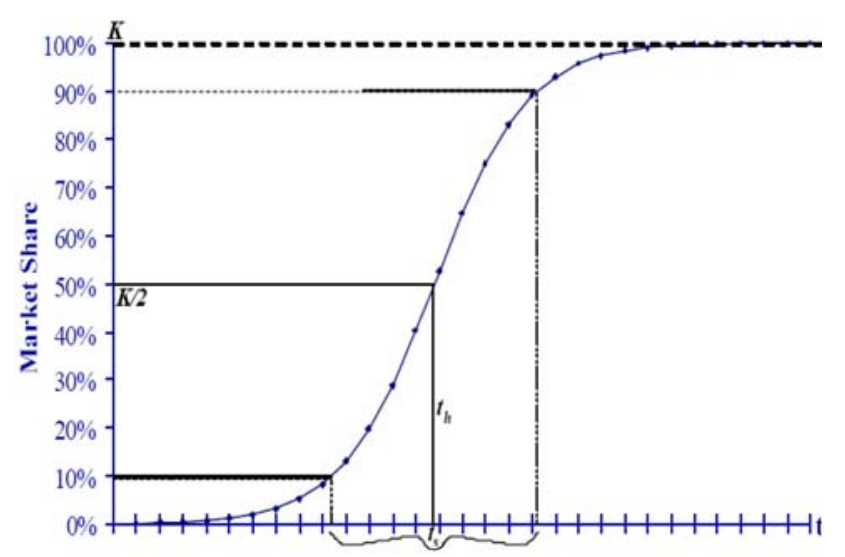

Fig. 1. Market penetration curve with s-curve type. target ratio

ts : time (year) that takes the market penetration ratio from 10 to $90 \%$

$c:$ constants

The S-curve parameter was determined using both methodologies, the Delphi method and life cycle theory, and determined by the following values. In this paper, the authors estimate the HTS power equipment launch from 2011, the imaginary launching year, not physical year.

- $(k=100 \%) \mathrm{K}$ indicates the final market penetration ratio of the target year, thus $k=100 \%$ in this paper.

- $(t h=2025)$ This paper assumes it requires approximately 15 years from launch, year to the year the market penetration ratio reaches $50 \%$, this was determined as 2025.

- $(t s=20)$ Considering the characteristics of the HTS technology and the discussions between HTS power equipment, this paper determines ts as 20 .

- $(c=7)$ Based on the life cycle theory of a general new technology product, the market penetration ratio was determined using a curve fitting simulation method.

As the $t s$ parameter becomes larger, the market penetration ratio increases slowly. When considering these parameters, the specific technology and product should be considered carefully.

\subsection{Calculation of HTS market volume}

The total market volume of the HTS power equipment is estimated employing the specified above assumptions and methodologies, using forecasts of the market volume of conventional power equipment reported by KOEMA reports in the domestic market. The marketable volume of each item is calculated as the conventional market volume, multiplied by a reasonable marketable ratio and market penetration ratio of a specific year, using the S-curve specifically described by Eq. (2).

(Market size of HTS each item in specific year) =

(Total conventional market size forecasts of each item in specific year $) \times($ Maximum marketable ratio of each HTS item in final year) $\times($ Market penetration ratio in specific year)

In Eq. (2), the maximum marketable ratio denotes the maximum permissible share of each piece of HTS equipment for the final target year, when considering HTS characteristics of the technology and conditions in the power industry market. For example, regarding specific HTS equipment, if we assume this maximum marketable ratio to be $30 \%$, this value means that specific HTS equipment could share only $30 \%$ of the total specific conventional power equipment. Moreover, the market penetration ratio is calculated by an S-curve from the FisherPry model, each year. For example, if the total market size is estimated by $\$ 100$ and assumes a maximum marketable ratio of $40 \%$, and the market penetration ratio is $50 \%$, then the market size of that piece of HTS equipment in that specific year is calculated as \$20 $(\$ 100 \times 0.4$ $\times 0.5)$.

\section{Forecasts of HTS Domestic Market Volume}

All data in this paper, until 2009, is the practical recorded data; after 2010 the authors estimate a $4.65 \%$ increase in the rate, considering the opinions of the KOEMA. The world popular trends of the T\&D facilities are expected as:

- The pursuit of automatic intelligent complex IT facilities, not single simple equipment

- Applications of new fusion and complex facilities such as HTS power equipment

- Creation of new global companies with new technologies, for example, HTS or smart-grid technology

After 2020, the increase rate in the market volume of each item is supposed to be $4.65 \%$, based on the previous average increase rate after 2000. The applied methodology for South Korea is identical to that of the world market, with exception to the following basic assumptions for the South Korean market:

- The target conventional power cable market volume is assumed as approximately $40 \%$ of the total T\&D line 
- The switchgear market for the FCL market estimation is targeted to a rating above $1 \mathrm{kV}$

- The transformer market is only focused on high-voltage levels

- The rotational machine (generator/motor) market is the sum of the ratings above $750 \mathrm{~kW}$

A practical HTS market volume is calculated as the marketable volume multiplied by the market penetration ratio of each year for each HTS item. This paper assumes 2011 as the launching year of the HTS equipment, and 2050 as the final target year. The S-curve is used to determine the market penetration ratio for each year. Based on the S-curve, this yearly market penetration ratio is calculated at $0.7 \%$ in 2011, the beginning year, and will increase from year to year, finally reaching $100 \%$ in 2047 . The market penetration ratio for each year is shown in Table 2.

The year 2015, the innovation stage of the HTS market, the market penetration ratio would be only $2.9 \%$. But as the price of HTS $2 \mathrm{G}$-wire is lower, and the reliability of HTS products higher, the market penetration ratio will rapidly increase.

The total marketable size of the HTS equipment in South Korea is expected to be $W 3,003$ billion in 2015 and finally $\mathrm{W} 14,737$ billion in 2050 .

The expected market volume of the HTS equipment, considering the estimating market penetration ratio, is expected to be approximately W88 billion. The market volume is predicted to increase rapidly to $\mathrm{W} 5,059$ billion in 2030 and finally reach W14,735 billion in 2050 . Furthermore, it is expected to reach $W 8,286$ billion within the HTS cable market, the biggest volume among all HTS items.

Table 1. Conventional market volume forecasts in South Korea

\begin{tabular}{lllllll} 
& & & & & \multicolumn{2}{c}{ (W 0.1Billion) } \\
\hline \hline & 2011 & 2015 & 2020 & 2030 & 2040 & 2050 \\
\hline Cable & 17,594 & 21,102 & 26,486 & 41,726 & 65,736 & 103,560 \\
Switchgear & 11,558 & 13,862 & 17,399 & 27,410 & 43,182 & 68,029 \\
Transformer & 23,401 & 28,067 & 35,228 & 55,498 & 87,432 & 137,741 \\
Generator & 16,817 & 20,170 & 25,317 & 39,885 & 62,834 & 98,989 \\
\& Motor & & & & & & \\
\hline Sum & 69,370 & 83,201 & 104,430 & 164,519 & 259,184 & 408,319 \\
\hline
\end{tabular}

Table 2. The market penetration ratio for each year

\begin{tabular}{ccccccc}
\hline \hline Year & 2011 & 2015 & 2020 & 2030 & 2040 & $2045 \sim$ \\
\hline $\begin{array}{c}\text { Yearly Market } \\
\text { Penetration Ratio (\%) }\end{array}$ & 0.7 & 2.9 & 14.8 & 85.2 & 99.5 & 100 \\
\hline
\end{tabular}

Table 3. Total marketable size in South Korea

\begin{tabular}{lrrrrrr} 
& & & & & \multicolumn{2}{c}{ (W 0.1Billion) } \\
\hline \hline Equipment & 2011 & 2015 & \multicolumn{1}{c}{2020} & 2030 & 2040 & 2050 \\
\hline Cable & 14,075 & 16,881 & 21,189 & 33,381 & 52,589 & 82,848 \\
Switchgear & 578 & 693 & 870 & 1,371 & 2,159 & 3,401 \\
Transformer & 7,020 & 8,420 & 10,568 & 16,649 & 26,230 & 41,322 \\
$\begin{array}{l}\text { Generator } \\
\text { \& Motor }\end{array}$ & 3,363 & 4,034 & 5,063 & 7,977 & 12,567 & 19,798 \\
\hline Sum & 25,036 & 30,028 & 37,690 & 59,378 & 93,545 & 147,369 \\
\hline
\end{tabular}

Table 4. Expected HTS market volume of South Korea (W 0.1Billion)

\begin{tabular}{lcrrrrr}
\hline \hline Equipment & 2011 & 2015 & 2020 & 2030 & 2040 & 2050 \\
\hline Market & 0.7 & 2.9 & 14.8 & 85.2 & 99.5 & 100 \\
Penetration Ratio & & & & & \\
Cable & 104 & 495 & 3,137 & 28,439 & 52,314 & 82,835 \\
Switchgear & 4 & 20 & 129 & 1,168 & 2,148 & 3,401 \\
Transformer & 52 & 247 & 1,565 & 14,185 & 26,093 & 41,316 \\
Generator & 25 & 118 & 750 & 6,796 & 12,501 & 19,795 \\
Motor & & & & & & \\
\hline Sum & 185 & 880 & 5,581 & 50,588 & 93,056 & 147,347 \\
\hline
\end{tabular}

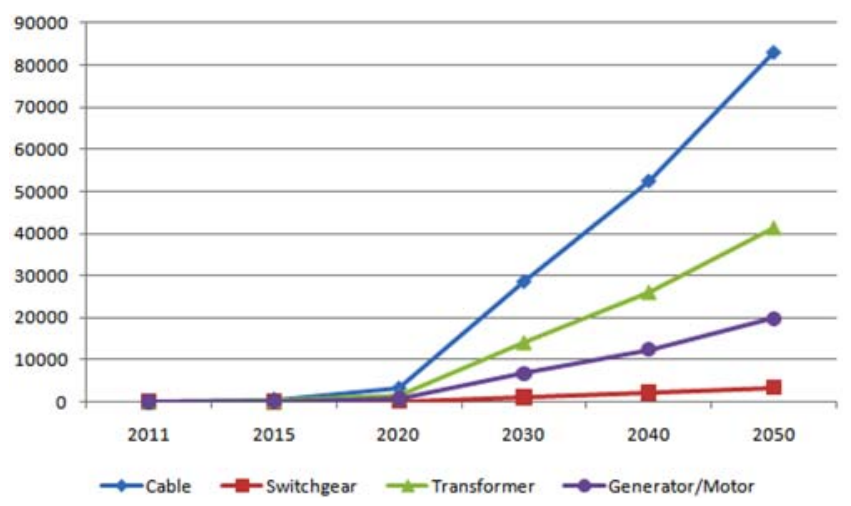

Fig. 2. Forecasts on the HTS market volume in South Korea.

\section{Conclusions}

This paper shows the expected market volume of four HTS items: HTS cable; transformers; FCL; rotational machines. The authors estimated the market volume from 2011, the supposed market-launching year, to 2050, the final year of market maturity. All of the market volume in this paper indicates the NPV (net present value) value transformed by 2011, the supposed launching year of the HTS equipment.

The market penetration ratio is calculated as $0.7 \%$ in 2011, the beginning year, and is expected to increase from year to year, finally reaching $100 \%$ in 2045 . As the price of HTS 2G-wire is lower, and the reliability of HTS 
products higher, the market penetration ratio will rapidly increase. The expected market volume of the HTS equipment, considering the estimating market penetration ratio, is only approximately W88 billion. Nevertheless, the same as in the case of the world market, the market volume will increase rapidly and is forecasted to be $\$ 5,059$ billion in 2030, reaching $W 14,735$ billion in 2050 .

\section{Acknowledgment}

This research was supported by a grant from KETEP (Korea Institute of Energy Technology Evaluation and Planning), funded by the Ministry of Knowledge and Economy, Republic of Korea.

\section{References}

[1] The World Market for Transmission \& Distribution Equipment and Systems 2008-2020, Goulden Reports, Wiltshire
(2009).

[2] The Prospects of Power Industry 2010, KOMEA, Seoul (2010).

[3] Long-term 4th Power Supply/Demand Plan, MOCIE, Korea (2008).

[4] Long-term Prospects for Transmission System, KEPCO, Seoul (2008).

[5] Korea's Smart Grid Roadmap 2030, http://www.smartgrid. or.kr

[6] Richard Silberglitt, Emile Ettedgui, and Anders Hove, Strengthening the Grid: Effect of High Temperature Superconducting Power Technologies on Reliability, Power Transfer Capacity and Energy, RAND Corp. (2002).

[7] Basic Planning for HTS $22.9 \mathrm{kV}$ Cable, KERI, Changwon (2002).

[8] Future Application Strategy for HTS $22.9 \mathrm{kV}$ Cable, KERI, Changwon (2003).

[9] P. E. Green and V. Srinivasan, Journal of Marketing 54, 3 (1990). 